\title{
Spatial-Temporal Data Model on Emergency : A Review
}

\author{
Jianhong Pan \\ 1 College of Physical Information \\ Engineering \\ Fuzhou University \\ 2 Information Department \\ Fujian Special Equipment \\ Inspection and Research Institute \\ Fuzhou, China \\ panjianhong@gmail.com
}

\author{
Qin Lin \\ College of Electronic Information \\ Science \\ FuJian Jiangxia University \\ Fuzhou, China \\ linqin1222@qq.com
}

\author{
Chenjie Cao \\ Chief Engineer Office \\ Fujian Special Equipment \\ Inspection and Research Institute \\ Fuzhou, China \\ $1198217595 @ q q . c o m$
}

\begin{abstract}
Based on the integration of space and time, TGIS system is the most important cornerstone for emergency rescue, while the spatial-temporal data model, in turn, is the vital foundation of TGIS. In recent years, various kinds of spatialtemporal data model have been developed. Consequently, this paper is trying to launch a research on the classification of these models and try to propose a discussion of models, including simple models, Space-time composites, models based on object and feature, and models based on object and feature. Meantime, the adaptability of the four types of models is also discussed in the paper, which shall provide reference for emergency space-time sequence and spatial-temporal data mining.
\end{abstract}

Keywords-Spatial-Temporal Data Model, Emergency, Data Model Classification

\section{INTRODUCTION}

Since the first GIS system was put into use in Canada in 1967, GIS has been developed as a key academic field. Application systems based on GIS emerge continuously. However, most GIS applications are static applications, featuring spatial factor and events only. In the event of emergency rescue, point, line and surface spreads usually have to be taken into consideration, which requires GIS has to take temporal factor into account, besides spatial factors and events. Temporal GIS (TGIS) simulates and expresses the changing geographic space more vivid with perfect timing analysis function. Spatial-temporal database is the organization foundation of TGIS and spatial-temporal data model[1] is its conceptual foundation. Since 1992, spatialtemporal data model has become one of the research hotspots in TGIS. The key to TGIS is to set up a spatial-temporal data model[2] integrating proper time and space. From the view of modeling method, spatial-temporal data modeling and spatial data modeling share a similar hierarchical division. Spatial-temporal data model focuses on how to describe the variation laws or phenomena of the spatial information changing with time by means of model. The keys to study spatial-temporal data model include spatiotemporal semantics description, data type and data operation of spatial-temporal integration, holonomic restriction, etc.
In 1992, the issue of Time in Geographic Information Systems[3] --academic dissertation of Gail Langra, marked TGIS (temporal geographical information system) has formally become a research direction in geographical information science.Till now, almost every scholar who engaged in temporal geographical information system research referenced the concept of spatial-temporal data model put forward by Gail Langran in varying degrees. It produces lasting influence on TGIS development. At present, many scholars throughout the world have made a great deal of research on the application of spatial-temporal data model. The representatives in this field include Langran[3], Peuquet[4] and Pelekis[5]. Some famous spatial-temporal data models[6] include space-time cube model, snapshots, the base state with amendments model, space-time composites(STC) model, 1NF relational spatial-temporal data model, N1NF relational spatial-temporal data model, event-based spatial-temporal data model, object-oriented spatial-temporal data model, Voronoi-based spatial-temporal data model, graph theory-based spatial-temporal data model, etc.

\section{ClassificATION METHODS AND CONDITIONS OF SPATIAL-TEMPORAL DATA MODELS}

There are many methods to classify spatial-temporal data models. They can be divided into two categories in terms of data structure, i.e., spatiotemporal data concept-related models and spatiotemporal data storage logic-related models[7]. They also can be divided into four categories in terms of characteristic, i.e., simple models, Space-time composites, models based on object and feature and models based on events and processes. Table I illustrates the classification conditions of spatial-temporal data models based on characteristic.

Table II illustrates the classification conditions of spatialtemporal data models based on spatial-temporal data structure. Reference [8] divides spatial-temporal data models into two categories according to emphasis on spatialtemporal objects, i.e., description mainly on spatial-temporal object state and description mainly on spatial-temporal object variation process. Reference [9] adds another category based on Reference [8]: description mainly on relationship of 
spatial-temporal object itself. In addition, there are many other classification methods but are not so common according to the results of literature retrieval.

TABLE I. CLASSIFICATION CONDITIONS OF SPATIAL-TEMPORAL DATA MODELS (BASED ON CHARACTERISTIC)

\begin{tabular}{|c|c|c|c|}
\hline \multirow{5}{*}{$\begin{array}{l}\text { Spatial- } \\
\text { Tempor } \\
\text { al Data } \\
\text { Models }\end{array}$} & $\begin{array}{c}\text { Classifica } \\
\text { tion } \\
\text { Method } \\
\end{array}$ & Category & Model Category \\
\hline & \multirow{4}{*}{$\begin{array}{l}\text { Based on } \\
\text { spatial- } \\
\text { temporal } \\
\text { object's } \\
\text { characteri } \\
\quad \text { stic }\end{array}$} & Simple models & $\begin{array}{l}\text { Sequential snapshot } \\
\text { model, base state with } \\
\text { amendments model }\end{array}$ \\
\hline & & $\begin{array}{l}\text { Space-time } \\
\text { composites }\end{array}$ & $\begin{array}{c}\text { Space-time composite } \\
\text { model, ST-object model }\end{array}$ \\
\hline & & $\begin{array}{c}\text { Models based } \\
\text { on object and } \\
\text { feature }\end{array}$ & $\begin{array}{c}\text { Object-oriented model, } \\
\text { voronoi-based model, } \\
\text { graph theory-based } \\
\text { spatial-temporal data } \\
\text { model, space-time cube } \\
\text { model }\end{array}$ \\
\hline & & $\begin{array}{c}\text { Models based } \\
\text { on events and } \\
\text { processes }\end{array}$ & $\begin{array}{l}\text { Event-based spatial- } \\
\text { temporal data model }\end{array}$ \\
\hline
\end{tabular}

TABLE II. CLASSIFICATION CONDITIONS OF SPATIAL-TEMPORAL DATA MODELS (BASED ON SPATIAL-TEMPORAL DATA STRUCTURE)

\begin{tabular}{|c|c|c|c|}
\hline \multirow{3}{*}{$\begin{array}{l}\text { Spatial- } \\
\text { Tempor } \\
\text { al Data } \\
\text { Models }\end{array}$} & $\begin{array}{c}\text { Classifica } \\
\text { tion } \\
\text { Method }\end{array}$ & Category & Model Category \\
\hline & \multirow{2}{*}{$\begin{array}{l}\text { Based on } \\
\text { spatial- } \\
\text { temporal } \\
\text { object } \\
\text { itself }\end{array}$} & $\begin{array}{c}\text { Spatiotempora } \\
\text { I data concept- } \\
\text { related model }\end{array}$ & $\begin{array}{c}\text { Space-time cube, } \\
\text { continuous snap- } \\
\text { shooting, base state } \\
\text { with amendments } \\
\text { model, space-time } \\
\text { composites, event-based } \\
\text { spatial-temporal data } \\
\text { models }\end{array}$ \\
\hline & & $\begin{array}{c}\text { Spatiotempora } \\
\text { I data storage } \\
\text { logic-related } \\
\text { model }\end{array}$ & $\begin{array}{c}\text { 1NF relational, N1NF } \\
\text { relational, object- } \\
\text { oriented, Voronoi-based } \\
\text { and graph theory-based } \\
\text { spatial-temporal data } \\
\text { models }\end{array}$ \\
\hline
\end{tabular}

III. DESCRIPTIONS ON MAJOR SPATIAL-TEMPORAL DATA MODEL

A. Continuous snapshots model, base state with amendments model and space-time composites model

Both Reference [4] and Reference [7] mention snapshots model. As shown in Fig. 1, Reference [4] also mentions sequent snapshots model. Reference [7] mentions snapshots incremental model, see Fig. 2. The features of snapshots model: every spatial-temporal object $(\mathrm{Si})$ is the ensemble of a series data status at specific time (ti), see Fig.I. Such original models precisely describe the status of spatial entity under time. However, such models would result in huge stored data information. Snapshots incremental model absorbs the concept of video technology, for example streaming media, which makes full-state records at the initial moment but only records the variation of specific position in subsequent moment. In this way, it avoids data redundancy results from full-state records, see Fig. 2. However, the model has a complicated data structure design and the data cannot be predicted beforehand. Moreover, such model requires calculation from the initial moment if restoration of spatial entity at any moment is needed. Virtually, it increases calculation amount. Reference [10] puts forward a dynamic 'version-difference' model, which makes improvements on incremental model. Although, it gains some effects, it fails to resolve the problems efficiently.

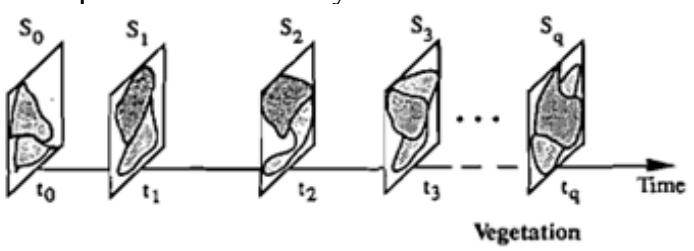

Figure 1.Sequent Snapshots Model[4]

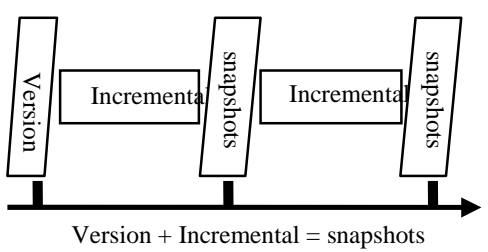

Figure 2.Snapshots Incremental Model[7]

Base-state improved model is similar with snapshots incremental model. It only records the base state and cumulative variation data. The difference is that the model records both base state and cumulative variation data of any moment, see Fig. 3. Therefore, the model enjoys huge storage capability and better performance in spatial-temporal recurrence.
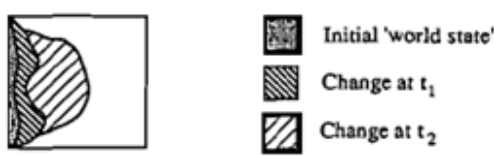

(a)
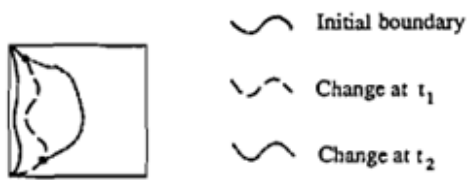

(b)

Figure 3.Base-State Improved Model[4]

Space-Time composites model stores the base state and the variation information of specific time. Compared to basestate improved model, it has a smaller storage capability. However, the slight variation increment brings much more physical defragmentation.

\section{B. Event-Based Spatial-Temporal Data Model}

Event-based spatial-temporal data model (ESTDM) was first put forward by Peuquet[4], see Fig. 4 The concept is to regard the variation of spatial-temporal object as an event. When these events are distributed to temporal axis, temporal series of the event will be formed. This model was put forward in early period and many scholars introduced 
improved models in the subsequent research. Wang Yanbo introduced intermediate state and ground state[11] to the model. Yu Zhiwen et al. introduced multiple states to the model and put forward distance factor of ground state of variable granularity[12]. All these improve the query efficiency of spatial-temporal data models. Based on the model, some scholars put forward expand models[13] that are based on events and features, see Fig. 5. The model believes that several geographical phenomena with common features will make up with a geographical event. The variation of the common features is the main factors to constitute an event.

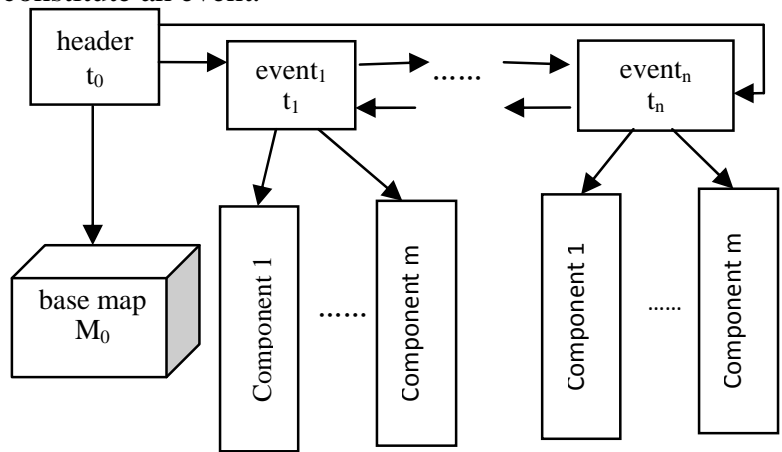

Figure 4.Diagram of ESTDM[4]

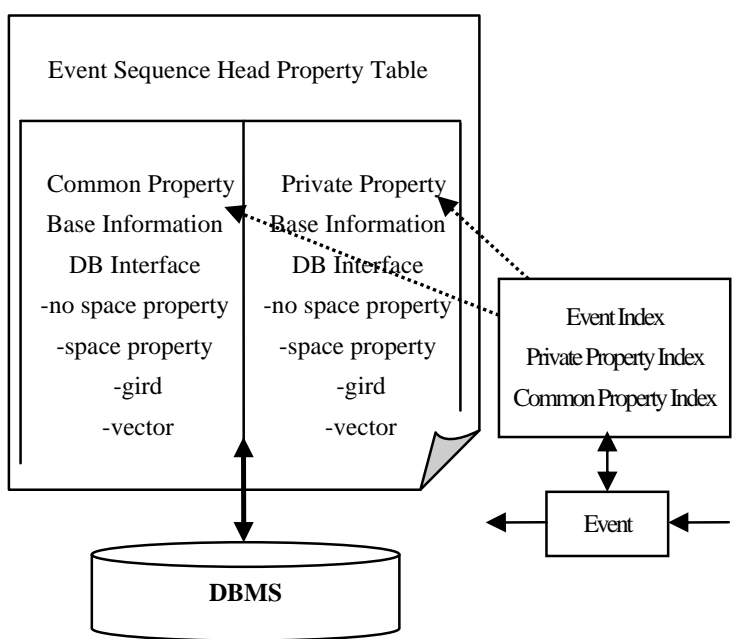

Figure 5.Diagram of Spatial-Temporal Data Concept Model Based on Events and Features

\section{Object-Oriented Spatial-Temporal Data Model}

Object-Oriented spatial-temporal data model[1] is the geospatial model established according to the concept and technology of object. It abstracts spatial entity as object and brings time dimension to the object. It also encapsulates the attributes and operation of the object, which breaks the limitation of traditional relational models and stimulates and expresses the geographical space correctly and comprehensively. It directly supports the object embedment and records expansion.
Object-Oriented spatial-temporal data model consists of spatial class, temporal class, attribute class, spatial temporal class, attribute temporal class, spatial temporal attribute point class, spatial temporal attribute line class and spatial temporal attribute area class. See Fig. 6.

Currently, there are few spatial-temporal data model based on object only[14]. Further research on uniform presentation model of changing data is needed in terms of spatial-temporal variation semantic.

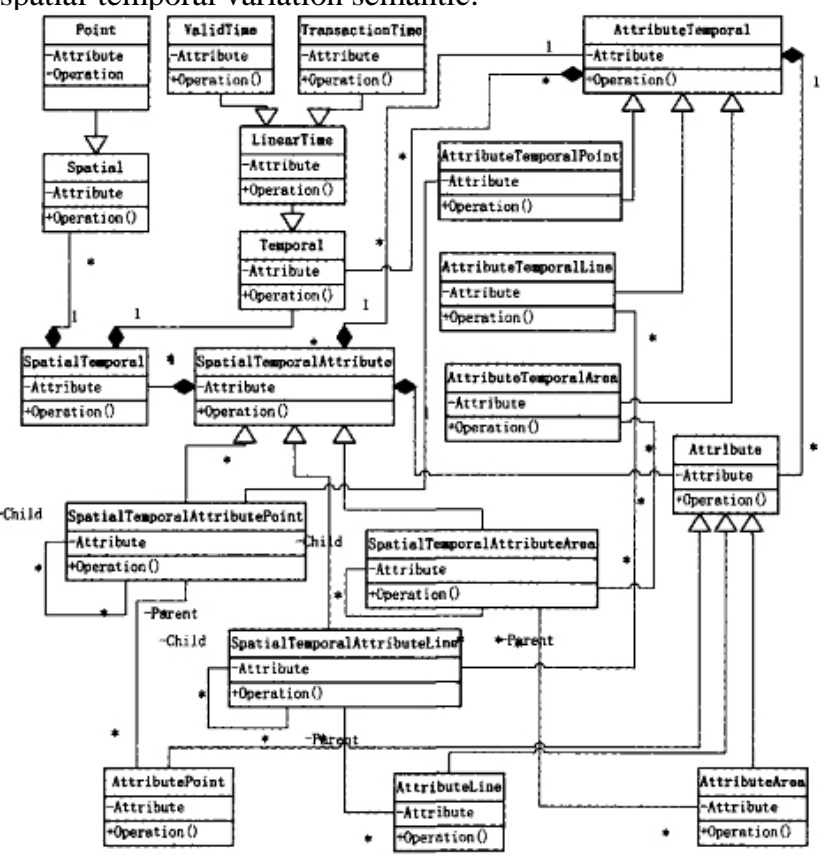

Figure 6.Diagram of Object-Oriented Spatial-Temporal Data Concept Model[1]

\section{Space-Time Cube Model}

Space-time cube model was put forward long ago. In 1990's, some scholars made a great deal of research on space-time cube model. Among them, Worboys[15] and Pang[16] were relatively excellent. Space-time cube model is regarded as a special example of object-based model, i.e., presenting all objects by means of geometry, topology and property. See Fig. 7.

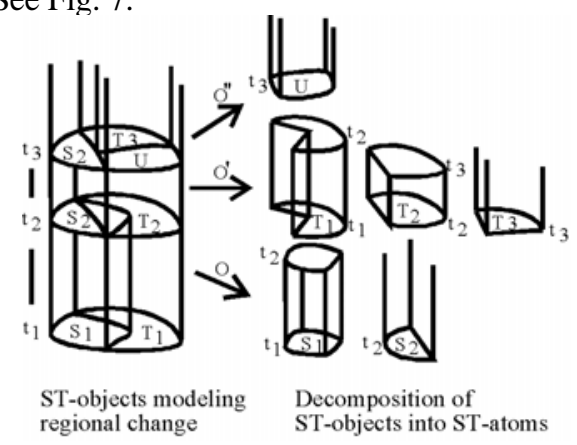

Figure 7.Diagram of Space-Time Cube Model[15] 


\section{SPATIAL-TEMPORAl DATA MODELS COMPARISON AND EMERGENCY APPLICATION ANALYSIS}

As is seen in Part I of this text, the academic circles have come to fruition by undertaking a comparatively large number of researches on spatial temporal data models. The author presents the adaptability to emergency application of four types of spatial-temporal data models by comparing main indexes like data storage space, data inquiry speed, types of supported changes, level of difficulty in capturing changes and supportability of movements and events. Please refer Table III for details.

TABLE III. SPATIAL-TEMPORAL DATA MODELS COMPARISON AND EMERGENCY APPLICATION ANALYSIS

\begin{tabular}{|c|c|c|c|c|}
\hline $\begin{array}{c}\text { Model } \\
\text { Type }\end{array}$ & $\begin{array}{c}\text { Supporting } \\
\text { changes }\end{array}$ & $\begin{array}{c}\text { Capturing } \\
\text { changes }\end{array}$ & $\begin{array}{c}\text { Supportability } \\
\text { of movements } \\
\text { and events }\end{array}$ & $\begin{array}{c}\text { Emergency } \\
\text { application } \\
\text { analysis }\end{array}$ \\
\hline $\begin{array}{c}\text { Simple } \\
\text { models }\end{array}$ & Discrete & Difficult & Unsupported & Unsuitable \\
\hline $\begin{array}{c}\text { Space- } \\
\text { time } \\
\text { composites }\end{array}$ & Discrete & Difficult & Unsupported & Unsuitable \\
\hline $\begin{array}{c}\text { Models } \\
\text { based on } \\
\text { object and } \\
\text { feature }\end{array}$ & $\begin{array}{c}\text { Discrete } \\
\text { and } \\
\text { continuous }\end{array}$ & Easy & movement & $\begin{array}{c}\text { Relatively } \\
\text { suitable }\end{array}$ \\
\hline $\begin{array}{c}\text { Models } \\
\text { based on } \\
\text { object and } \\
\text { feature }\end{array}$ & Discrete & Easy & Both & Suitable \\
\hline
\end{tabular}

\section{CONCLUSIONS}

For GIS, the spatial-temporal data models that simultaneously presents space and time is of vital importance for emergency geographical information application. The development of TGIS drives many foreign and domestic scholars to the study of spatial-temporal data models. The author refers to the summary and literatures on spatialtemporal data models and finds out scholars, in particular, domestic scholars do not describe the essence of models adequately.

While studying the existing spatial-temporal data models, the author starts with the expansion and relationships of various models to provide reference for carrying out spatialtemporal series analysis on emergency and data excavating and even establishing spatial-temporal data models for emergency system.

\section{REFERENCES}

[1] W. Song, J.Y. Wang and J.H. Guo, "An Object-Oriented Spatialtemporal Data Model," Journal of Geomatics Science and Technology, vol.23, pp. 235-238, 2006.

[2] H.F. Wang, "Spatio-temporal Data Model and TGIS," Geomatics \& Spatial Information Technology, vol.29, pp. 11-13, 2006.

[3] G. Langran, Time in Geographic Information System. Taylor \& Francis, Washington DC., 1992.

[4] D.J. Peuquet and D. Niu, "An event-based spatiotemporal data model (ESTDM) for temporal analysis of geographical data," International Journal of Geographical Information Science, vol.9, pp. 7-24, 1995.

[5] Z.C. Yin and Q. Li, "Research on Spatial-temporal Data Model for Land Subdivision," Remote Sensing For Land \& Resources, vol.14, pp. 70-75, 2002.

[6] Z.Q. Huang and X.Z. Feng, "A Study of Spatio-temporal Process Modeling Based on Petri Net for Land Alteration," Acta Geodaetica Et Cartographic Sinica, vol.34, pp. 239-245, 2005.

[7] J.F. She, X.Z. Feng and J.K. Du, "A Review on Progress in Spatiotemporal Data Modeling," Journal of Nanjing University (Natural Sciences), vol.41, pp. 259-267, 2005.

[8] Y.L. Li, "About the Study of the Spatio-temporal Data Models," Journal of Hunan Industry Polytechnic, vol.7, pp. 21-23, 2007.

[9] X. Chen, L. Songnian and J. Zhu, "Spatiotemporal Data Model Related Concepts and Its Classifications," Hydrographic Surveying and Charting, vol.29, pp. 74-81, 2009.

[10] J.J. Tian, X.M. Tang, P. Yang, H.B. Wang and L. Zhai, "Study and application of dynamic database model," Science of Surveying and Mapping, vol.31, pp. 123-125, 2006.

[11] Y.B. Wang, "The Dynamic Compression of Temporal GIS Data," Chinese Journal of Engineering Geophysics, vol.2, pp. 60-63, 2005.

[12] Z.W. Yu, L.T. Zhang and Y.H. Wu, "The Extention of Spatiotemporal Data Model Based on Base State with Amendments," Acta Scientiarum Naturalium Universitatis Sunyatseni, vol.42, pp. 100-103, 2003.

[13] Q.J. Chen and H.Q. Xie, "Research on organization method for spatio-temporal data of land reclamation system in mining area," Journal of Liaoning Technical University, vol.22, pp. 717-720, 2003.

[14] C.B. Wang, J. Zhang and T. Jiang, "Application and research of an event-based spatio-temporal data model," patio-temporal data model. Science of Surveying and Mapping, vol.30, pp. 67-69, 2005.

[15] M.F. Worboys, "Object-oriented models of spatiotemporal information," Proceedings of GIS/LIS '92 Annual Conference, Dec. 1992, pp. 825-834.

[16] Y.C. Pang, Development of Process-based Model for Dynamic Interaction Process in Spatiotemporal GIS, HK: The Hong Kong Polytechnic University, 1999. 